\title{
INFLUÊNCIA DO GÊNERO NOS TESTES DE VO2MÁX E RAST EM ATLETAS DE ATLETISMO
}

\author{
Ronaldo Nascimento Maciel \\ Mestre em Ciência da Motricidade Humana / UCB / RJ \\ Coordenadoria Extraordinária de Apoio ao Escolar de Macaé - CEMEAES / FESPORTUR / RJ \\ rnmvolei@hotmail.com \\ Hiller Franco Entringer \\ Graduado em Educação Física / UFRRJ / RJ \\ Coordenadoria Extraordinária de Apoio ao Escolar de Macaé - CEMEAES / FESPORTUR / RJ \\ hillerfranco@hotmail.com \\ Marcelo da Silva Machado \\ Mestre em Saúde Pública / FIOCRUZ / RJ \\ Coordenadoria Extraordinária de Apoio ao Escolar de Macaé - CEMEAES / FESPORTUR / RJ \\ marcelodasilva@macae.rj.gov.br

\begin{abstract}
Anderson Pontes Morales
Mestre em Ciência da Motricidade Humana / UCB / RJ

Coordenadoria Extraordinária de Apoio ao Escolar de Macaé - CEMEAES / FESPORTUR / RJ

andersonmrl@hotmail.com
\end{abstract}

\section{RESUMO}

A manutenção de níveis ótimos de potência muscular e a recuperação rápida são imprescindíveis para o bom desempenho no atletismo. O objetivo do estudo foi de comparar entre os gêneros a média dos escores de VO2máx e do RAST e correlacionar os níveis de VO2 máx e o índice de fadiga com os níveis de potência máxima e média. A amostra foi constituída de $n=24$ atletas com $16.3 \pm 2.51$ anos, sendo $n=12$ do Gênero Masculino (GM) e $n=12$ do Gênero Feminino (GF). Considerou os níveis significativos $p<0,05$. Foram

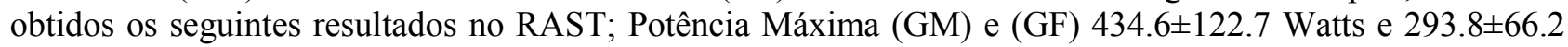
Watts $(\mathrm{p}=0.03)$; Potência Média 367 \pm 101.9 Watts; $226.6 \pm 53.0$ Watts $(\mathrm{p}=0.02)$ e na Potência Mínima $302.5 \pm 80.2$ Watts e $237.2 \pm 206.6$ Watts $(\mathrm{p}=0.00)$. Nos valores relativos, $(\mathrm{GM})$ e $(\mathrm{GF})$ a Potência Máxima foi de $7.05 \pm 1.70 \mathrm{Watts} / \mathrm{Kg}$ e $5.49 \pm 1.22 \mathrm{Watts} / \mathrm{Kg}$ ( $\mathrm{p}=0.02)$; Potência Média $5.95 \pm 1.36 \mathrm{Watts} / \mathrm{Kg}$ e $4.22 \pm 0.99$ Watts/Kg ( $\mathrm{p}=0,01$ ); Potência Mínima 4.89 \pm 1.07 Watts/Kg e 3.06 \pm 1.27 Watts/Kg ( $\mathrm{p}=0,01$ ). No VO2máx o (GM) (GF) obtiveram 41.1 \pm 6.2 ml.(kg.min) $-^{-1}$ e $32.6 \pm 6.4$ ml.(kg.min) $-^{-1}(\mathrm{p}=0.00)$. Encontrou uma correlação no VO2máx e Potência Máxima $(\mathrm{r}=0.6744$ / $\mathrm{p}=0.01)$, VO2máx e a Potência Média $(\mathrm{r}=0.8227 / \mathrm{p}=0.00)$, Potência Máxima e o Índice de Fadiga $(\mathrm{r}=0.7326 / \mathrm{p}=0.00)$. Conclui-se que as diferenças significativas encontradas nos valores de potências máxima, média e mínima (Watts) (Watts/Kg), ratificam estudos anteriores. A correlação do VO2máx e a potência média, apontam para uma possível relação direta, fato que, se confirmado, pode ajudar a entender resultados de atletas de vários níveis.

Palavras-chave: Atletismo; Potência Muscular; VO2 máx.

\section{ABSTRACT}

Maintaining optimal levels of muscle power and rapid recovery are essential for good performance in athletics. O objective was to compare between genders the mean scores of VO2peak and RAST and compare the levels of VO2peak and the fatigue index with the levels of Peak Power and Average. The sample consisted of $n=24$ athletes with $16.3 \pm 2.51$ years, $n=12$ males $(G M)$ and $n=12$ females (GF). Significant levels $\mathrm{p}<0.05$. The following results were obtained in RAST; Peak Power (GM) and (GF) 434.6 \pm 122.7 and $293.8 \pm 66.2$ Watts $(\mathrm{p}=0.03)$; Average Power $367 \pm 101.9$ Watts, $226.6 \pm 53.0$ Watts $(\mathrm{p}=0.02)$ and Minimum Power $302.5 \pm 80.2$ and $237.2 \pm 206.6$ Watts $(\mathrm{p}=0.00)$. In relative terms, $(\mathrm{GM})$ and $(\mathrm{GF})$ the Peak Power was $7.5 \pm 1.70$ watts $/ \mathrm{kg}$ and $5.49 \pm 1.22$ watts $/ \mathrm{kg}(\mathrm{p}=0.02)$; Average Power $5.95 \pm 1.36$ watts / $\mathrm{kg}$ and $4.22 \pm 0.99$ watts $/ \mathrm{kg}(\mathrm{p}=0.01)$; Power Minimum $4.89 \pm 7.1 \mathrm{Watts} / \mathrm{kg}$ and $3.06 \pm 1.27$ watts 
$/ \mathrm{kg}(\mathrm{p}=0.01)$. In the VO2max (GM) (GF) obtained $41.1 \pm 6.2 \mathrm{ml}$. (Kg.min) $-{ }^{1}$ and $32.6 \pm 6.4 \mathrm{ml} .(\mathrm{Kg} \cdot \mathrm{min})$ $-{ }^{1}(\mathrm{p}=0.00)$. Correlation found in VO2peak and Peak Power $(\mathrm{r}=0.6744 / \mathrm{p}=0.01)$, VO2peak and Average Power $(r=0.8227 / p=0.00)$, Peak Power and Fatigue Index $(r=0.7326 / p=0.00)$. We conclude that the significant differences found in values of Peak Power, Average and Minimum (Watts) (Watts / kg), confirms previous studies. The correlation between VO2peak and Average Power, point to a possible direct relationship, a fact which, if confirmed, may help to understand outcomes of various levels of athletes.

Keywords: Athletics; Muscle Power; VO2peak.

\section{INTRODUÇÃO}

O atletismo pode ser caracterizado pela diversidade de provas, sendo que cada uma delas é marcada pela presença de condições específicas do treinamento e presença de elementos básicos, como correr, saltar, lançar ou arremessar (MACENA, 2011). Na realização destes elementos com eficiência, destaca-se a potência muscular, caracterizada como a taxa de realização de trabalho em determinado período e, a resistência cardiovascular e pulmonar, permitindo uma rápida recuperação depois ou entre os esforços.

O desempenho em competições com várias provas em um só dia, como acontece nas provas de atletismo e natação (DENADAI et al., 1996), pode ser influenciado negativamente pela queda na razão ATP/ADP em atividade contrátil intensa, levando à inibição do processo contrátil e instalando a fadiga muscular (GASTIN, 2001; LAMB; RECUPERO \& STEPHENSON, 1991). Estas informações poderão ser mais acentuadas quando são comparadas entre os gêneros, visto que homens apresentam maiores valores de VO2max, maiores concentrações de hemoglobina e volume de sangue total do que as mulheres, o que garante que mais $\mathrm{O} 2$ seja carreado e ofertado aos tecidos (AKALAN; KRAVITZ \& ROBERGS, 2004; HERDY \& UHLENDORF, 2011).

Contradições na literatura são mostradas, quanto à resposta de homens e mulheres frente à manutenção de torque relativo no exercício físico. Hunter et al. (2004), encontraram estas diferenças quando homens e mulheres foram submetidos a séries intermitentes ( $6 \mathrm{~s}$ de contração e $4 \mathrm{~s}$ de descanso) de contrações submáximas $(50 \% \mathrm{CVM})$ dos músculos flexores do cotovelo, onde verificaram que as mulheres desenvolviam torques semelhantes aos dos homens para a mesma tarefa de força, e que estas não eram estatisticamente diferentes entre si. Clark et al. (2005) sugerem que há diferenças no fluxo sanguíneo, ou ainda, no metabolismo muscular entre gêneros, conferindo às mulheres vantagens sobre os homens na manutenção da capacidade de ressíntese de ATP, determinado pela uma maior capacidade relativa de recrutamento das unidades motoras (UMs) em alta intensidade de trabalho muscular comparadas aos homens.

Segundo Kagaya \& Homma (1997) a força muscular inferior absoluta mostrada pelas mulheres deve exigir menor demanda de oxigênio muscular e resultar em uma menor compressão mecânica da vascularização do tecido ativo, permitindo assim um menor desequilíbrio entre a oferta e a demanda de sangue. É constatado em mulheres que a fatigabilidade do músculo esquelético diminuem à medida que aumenta a intensidade de contração (HICKS; KENT-BRAUN \& DITOR, 2001). Os mesmos autores (2001) relatam ainda que os possíveis mecanismos para essa diferença entre os gêneros incluem fatores relacionados à massa muscular, utilização do substrato, morfologia muscular e ativação neuromuscular. Já no estudo de Maughan et al. (1986), as mulheres tinham um tempo maior de resistência ao realizar contrações de baixa intensidade com os músculos extensores do joelho, mas essa diferença diminuiu durante as contrações de alta intensidade quando homens e mulheres experimentaram oclusão circulatória.

Estas observações levantaram questões das contribuições relativas da manutenção da potência muscular de membros inferiores em mulheres comparadas aos homens, resultando em possíveis informações relevantes para a prescrição de treinamento. Leva-se ainda em conta que os níveis ótimos de potência muscular e a recuperação rápida proporcionada pela resistência cardiovascular e pulmonar entre as ações intensas, são imprescindíveis para o bom desempenho do atleta de atletismo, tornando então analisar os efeitos agudos de sucessivos estímulos de alta intensidade (sprints) sobre a capacidade de gerar potência muscular. 
Sendo assim, (2) dois objetivos foram formulados no estudo: comparar entre os gêneros a média dos escores do Teste de Corrida de 2.400m (Cooper) e do Running-based Anaerobic Sprint Test (RAST); correlacionar os níveis de VO2 máx e o índice de fadiga com os níveis de Potência Máxima e Potência Média.

\section{METODOLOGIA}

\subsection{Amostra}

A amostra foi constituída de $n=24$ atletas com idade média de $16.3 \pm 2.51$ anos, voluntários, da equipe de atletismo do CEMEAES (Coordenadoria Extraordinária de Apoio ao Escolar de Macaé, RJ), sendo n=12 do Gênero Masculino (GM) e n=12 do Gênero Feminino (GF). Como critério de inclusão foram selecionados os atletas com mais de (1) um ano de treinamento no atletismo do CEMEAES nas provas de média e de longa distância, que estivessem participando plenamente das atividades de treinamento e competições da equipe. Utilizou-se como critério de exclusão, atletas que apresentasse histórico de lesão muscular diagnosticada pela equipe médica do CEMEAES.

\subsection{Procedimentos Experimental}

Apresentou-se aos responsáveis dos atletas o Termo de Consentimento Livre e Esclarecido, conforme resolução 196/1996 do Conselho Nacional de Saúde. A presente pesquisa teve seu projeto de pesquisa submetido e aprovado pelo Comitê de Ética em Pesquisa Envolvendo Seres Humanos dos Institutos Superiores de Ensino do CENSA (ISECENSA-RJ) sob o $\mathrm{n}^{\circ}$ de protocolo (1245.0.000.413-11). Os testes foram divididos em 2 (dois) dias não consecutivos com um intervalo de 4 (quatro) dias. No $1^{\circ}$ dia foi avaliada a massa corporal (balança Filizola ${ }^{\circledR}$ ) dos atletas que em seguida realizaram um aquecimento de 10 (dez) minutos antes da sessão do teste. Os atletas foram chamados aleatoriamente para realizarem uma bateria de seis corridas (sprints) de 35 metros com intervalo de 10 (dez) segundos entre cada corrida. Foram utilizados 3 (três) avaliadores cada um com um cronômetro (SL888T Oregon ${ }^{\circledR}$ ), sendo que um ficou posicionado no meio da distância a ser percorrida, para marcar os tempos dos tiros (pesquisador); os outros dois (técnico e auxiliar) cada um de um lado na linha final dos 35 metros para marcar os 10 segundos de descanso. Para cálculo do Running-based Anaerobic Sprint Test (RAST) (ZAGATTO; BECK \& GOBATTO, 2009; GHANBARI-NIAKI; KRAEMER \& SOLFANI, 2010) foram utilizados as seguintes fórmulas:

Velocidade: distância/tempo;

Aceleração: velocidade/tempo;

Força: peso/aceleração;

Potência: A potência (P; W) para cada esforço foi obtida através do produto entre a massa corporal total do atleta (MC; $\mathrm{kg}$ ) e a distancia de cada esforço elevada ao quadrado $(35 \mathrm{~m})$. O resultado foi divido pelo tempo de cada esforço (T; s) elevado ao cubo.

$$
\text { Equação }-\mathrm{P}(\mathrm{W})=\frac{\mathrm{MC} \times 35^{2}}{\mathrm{~T}^{3}}
$$

O cálculo da potência das seis corridas é então determinado:

Potência Máxima: o valor mais alto (Watts) ou (Watts/Kg) ;

Potência Mínima: o valor mais baixo (Watts) ou (Watts/Kg);

Potência Média: a soma de todos os seis valores de potência, dividido por seis;

Índice de fadiga: (potência máxima - potência mínima) / tempo total para as 6 (seis) corridas de curta distância (Watts/Seg). Todas as variáveis foram mensuradas em valores absolutos (Watts) e relativos (Watts/Kg - divide-se o resultado pelo peso corporal). 
No $2^{\circ}$ dia após um aquecimento de 10 (dez) minutos, os atletas realizaram uma corrida que consistiu em (7) sete voltas na pista mais a distância de 160 metros no menor tempo possível, totalizando 2.400 metros. Foram utilizados 5 (cinco) avaliadores cada um com um cronômetro marcando o tempo de 2 (dois) atletas. Para cálculo do Teste de Corrida de 2.400m (Cooper) (COOPER, 1968) foi utilizada a seguinte fórmula:

$$
\begin{aligned}
& \text { VO2máx ml (kg.min })^{-1}=(2.400 \times 60 \times 0,2)+3,5 \mathrm{ml}(\mathrm{kg} \cdot \min )-^{-1} / \mathrm{D} \\
& \text { D - Duração em segundos. }
\end{aligned}
$$

Para que existisse uma igualdade de condições para todos os avaliados nos dois dias, os testes foram realizados entre as $14 \mathrm{~h} 30 \mathrm{minh}$ e $16 \mathrm{~h} 30 \mathrm{~min}$. Foi utilizado a pista de atletismo do Forte Marechal Hermes (Macaé, RJ), que possui 320 metros.

\subsection{Análise Estatística}

A normalidade dos dados foi verificada com a aplicação do teste de Shapiro Wilk: Teste de Corrida de $2.400 \mathrm{~m}$ GM ( $\mathrm{p}=0.41)$ GF ( $\mathrm{p}=0.06)$ e no Running-based Anaerobic Sprint Test (RAST) Potência Máxima GM ( $\mathrm{p}=0.55)$ GF ( $\mathrm{p}=0.80)$; Potência Média GM ( $\mathrm{p}=0.44)$ GF ( $\mathrm{p}=0.23)$; Potência Mínima GM ( $\mathrm{p}=0.56)$ GF $(\mathrm{p}=0.22)$. Os resultados das variáveis analisadas foram apresentados como média \pm desvio-padrão. Para avaliar as respostas intergrupos foi utilizado o teste " $t$ " independente, permitindo testar hipóteses sobre valores médios paramétricos de variáveis quantitativas entre dois grupos (Gênero Masculino GM e Gênero Feminino GF). Para a verificação do coeficiente de correlação foi utilizada a correlação de Pearson, onde os 6 (seis) melhores escores no VO2 máx do gênero masculino e feminino foram selecionados pelo percentil 50, de acordo com a classificação da tabela de COOPER (Regular / Superior) (COOPER, 1982). Considerou os níveis significativos $\mathrm{p}<0,05$. Os dados oriundos dos procedimentos descritos acima foram analisados pelo programa 5.0 GraphPad Prism ${ }^{\circledR}$ versão 5.0 (Graphpad Software, Inc., www.graphpad.com).

\section{RESULTADOS}

A idade e o perfil antropométrico (massa corporal), foram mensurados para verificar se a população participante era homogênea. As características dos indivíduos podem ser observadas na tabela 1.

Tabela 1. Características dos sujeitos (média \pm desvio padrão).

\begin{tabular}{lccc}
\hline Características & Gênero Masculino $(\mathrm{GM})$ & Gênero Feminino $(\mathrm{GF})$ & $\mathrm{p}=$ \\
\hline $\mathrm{n}=$ & 12 & 12 & \\
Idade (anos) & $16.7 \pm 3.13$ & $16 \pm 1.75$ & 0.23 \\
Massa corporal $(\mathrm{Kg})$ & $61.4 \pm 12.39$ & $50.8 \pm 2.46$ & 0.09 \\
\hline
\end{tabular}

Não ocorreu diferença significativa $(p>0,05)$.

A figura 1 representa os escores de potência muscular dos membros inferiores entre os gêneros, tendo no Gênero Masculino (GM) e Gênero Feminino (GF) a Potência Máxima de 434.6 \pm 122.7 Watts e 293.8 \pm 66.2 Watts $(\Delta 67 \%)$, na Potência Média $367 \pm 101.9$ Watts e $226.6 \pm 53.0$ Watts $(\Delta 61 \%)$ e na Potência Mínima 302.5 \pm 80.2 Watts e $237.2 \pm 206.6$ Watts $(\Delta 78 \%)$ respectivamente, havendo diferenças significativas entre os Gêneros na Potência Máxima $(\mathrm{p}=0.03)$, Média $(\mathrm{p}=0.02)$ e Mínima $(\mathrm{p}=0.00)$. Já em valores relativos, no Gênero Masculino (GM) e Gênero Feminino (GF) a Potência Máxima foi de $7.05 \pm 1.70 \mathrm{Watts} / \mathrm{Kg}$ e $5.49 \pm 1.22 \mathrm{Watts} / \mathrm{Kg}(\Delta 77 \%)$, na Potência Média $5.95 \pm 1.36 \mathrm{Watts} / \mathrm{Kg}$ e $4.22 \pm 0.99 \mathrm{Watts} / \mathrm{Kg}(\Delta 71 \%)$ e na Potência Mínima $4.89 \pm 1.07$ Watts/Kg e $3.06 \pm 1.27$ Watts $/ \mathrm{Kg}(\Delta 62 \%)$ respectivamente, havendo diferenças significativas em todas as varáveis; Potência Máxima $(\mathrm{p}=0.02)$, Média $(\mathrm{p}=0,01)$ e Mínima $(\mathrm{p}=0.01)$. 
RAST (Running-based Anaerobic Sprint Test)
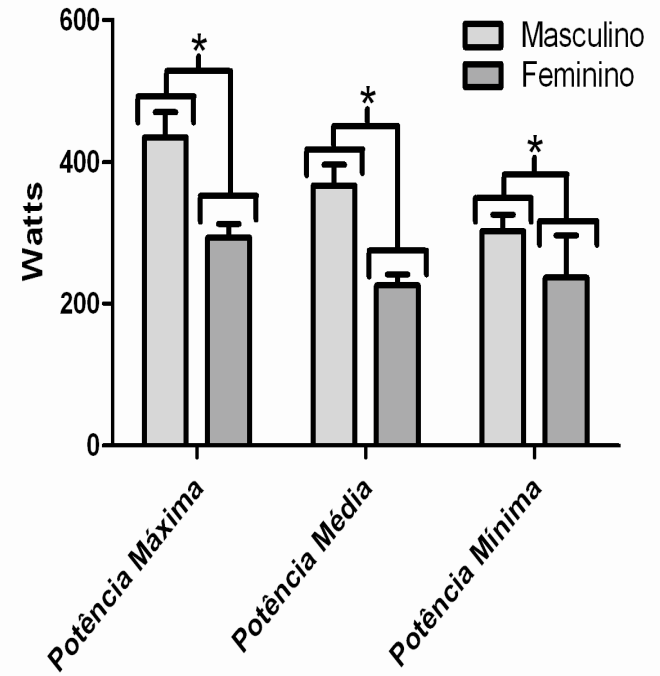

RAST (Running-based Anaerobic Sprint Test)
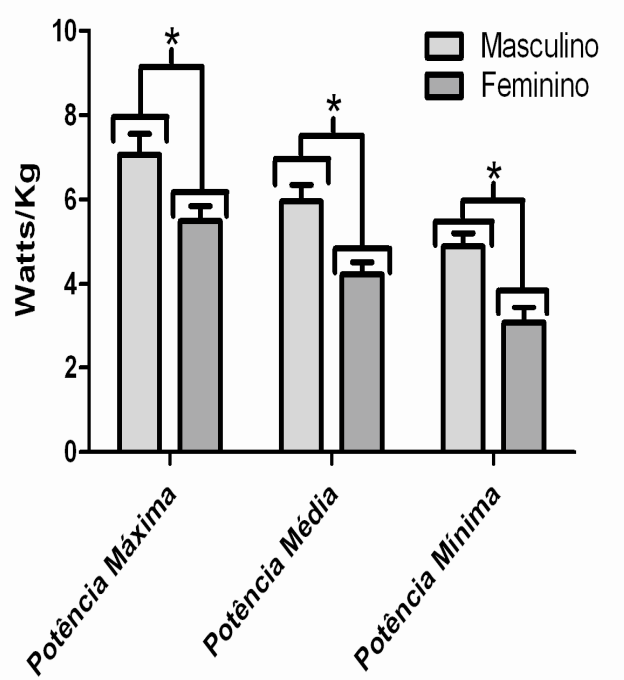

* diferente em relação ao gênero feminino $(\mathrm{p}<0,05)$.

Figura 1: Comparação dos resultados entre os gêneros no teste Running-based Anaerobic Sprint Test (RAST).

A figura 2 representa os escores de VO2máx dos atletas de atletismo, tendo o Gênero Masculino

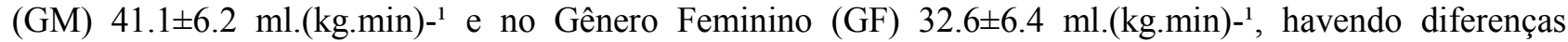
significativas entre os Gêneros $(\mathrm{p}=0.00)$.

COOPER (Teste de Corrida 2.400 metros)

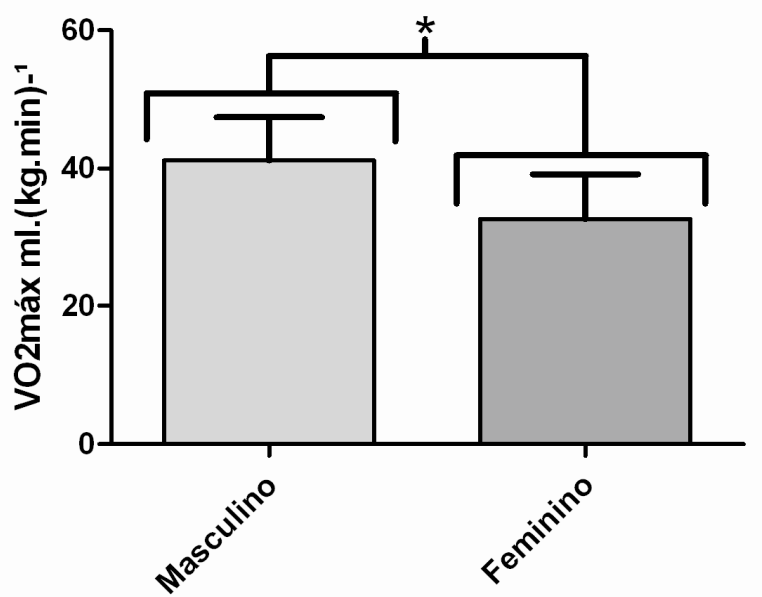

* diferente em relação ao gênero feminino $(\mathrm{p}<0,05)$.

Figura 2: Comparação dos resultados entre os gêneros no teste de COOPER (Teste de Corrida de 2.400m).

A figura 3 representa uma correlação média alta $(\mathrm{r}=0.6744 / \mathrm{p}=0.01 / \mathrm{r} 2=0.4549)$ entre o VO2máx e Potência Máxima, já em relação o VO2máx e a Potência Média encontrou-se uma correlação alta ( $\mathrm{r}=$ $0.8227 / \mathrm{p}=0.00 / \mathrm{r} 2=0.676$ ) dos 6 (seis) melhores escores do Gênero Masculino (GM) e Gênero Feminino (GF). 

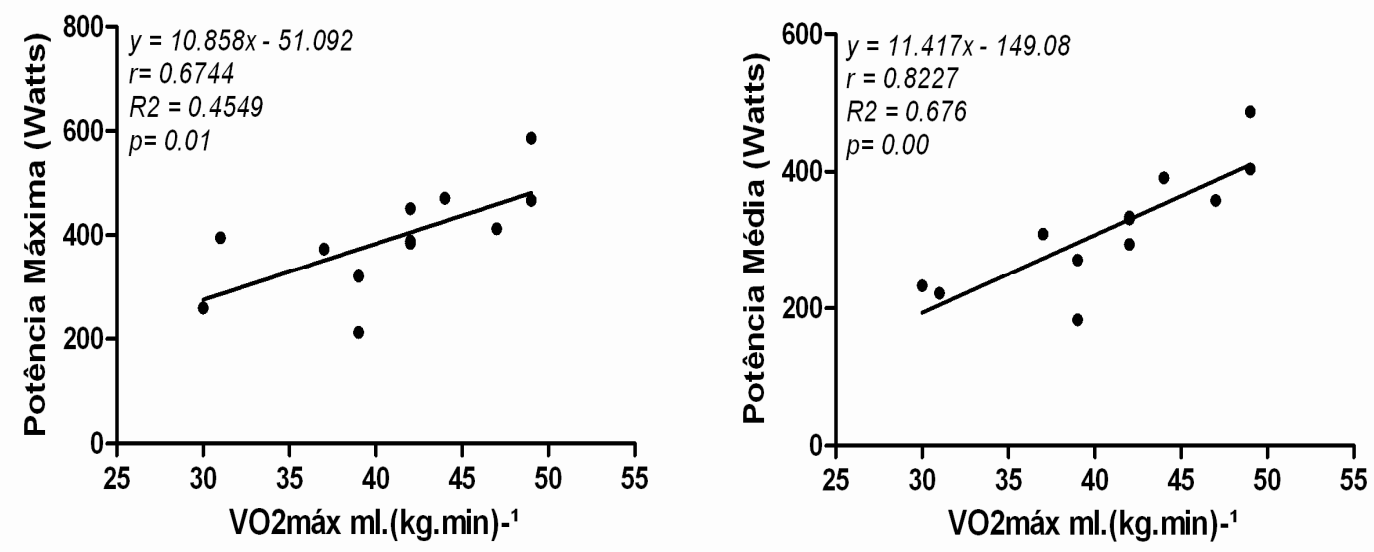

Figura 3: Correlação dos resultados entre o VO2máx e Potência Máxima, VO2máx e Potência Média.

A figura 4 representa uma correlação média alta $(\mathrm{r}=0.7326 / \mathrm{p}=0.00 / \mathrm{r} 2=0.5397)$ entre a Potência Máxima e o Índice de Fadiga, já em relação á Potência Média e o Índice de Fadiga não encontrou uma correlação $(\mathrm{r}=0.4025 / \mathrm{p}=0.162 / \mathrm{r} 2=0.162)$ dos 6 (seis) melhores escores do Gênero Masculino (GM) e Gênero Feminino (GF).
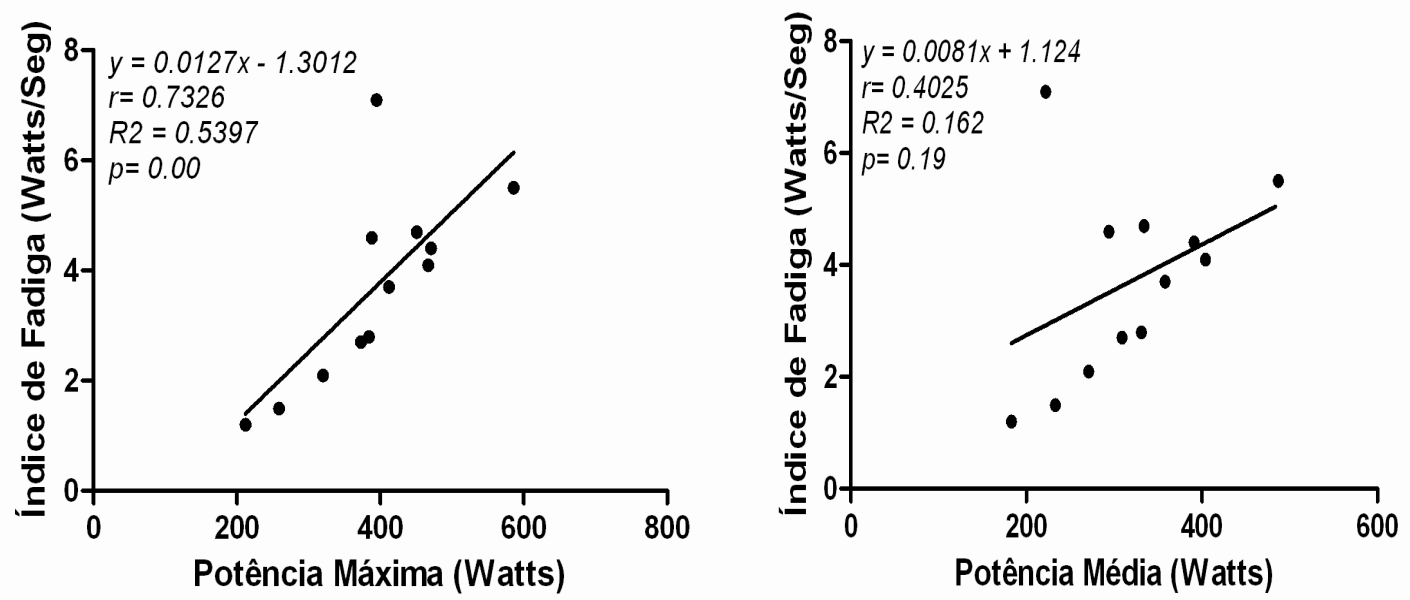

Figura 4: Correlação dos resultados entre a Potência Máxima e Índice de Fadiga Muscular, Potência Média e Índice de Fadiga Muscular.

\section{DISCUSSÃO}

É bem documentado que o VO2máx é uma importante variável fisiológica relacionada ao transporte de $\mathrm{O} 2$ e ao metabolismo muscular, refletindo como se ajustam e interagem os sistemas cardíaco, muscular, respiratório e vascular. Hipóteses apontam para uma possível diferença das respostas frente ao esforço das atividades denominadas aeróbias entre os gêneros masculino e feminino, havendo, entretanto, contradições sobre as possíveis vantagens e desvantagens de cada gênero (AZEVEDO et al., 2010).

Azevedo et al. (2010) em um estudo com indivíduos sedentários, encontraram diferenças significativas ao comparar o VO2máx entre os gêneros. Estes resultados estão de acordo com Herdy \& Uhlendorf (2011), que fizeram uma pesquisa com uma população extremamente numerosa (3922 pessoas) e dividiram esta amostra em indivíduos ativos e sedentários, tendo cada grupo seis estratificações etárias, encontrando diferenças significativas na comparação entre os gêneros em quase todos os grupos.

A utilização do Running-based Anaerobic Sprint Test (RAST) se deve a idéia de que testes que utilizam múltiplos sprints são os mais indicados para predizer a performance anaeróbia dos atletas (JÚNIOR 
et al., 2008). Nestas atividades, o desempenho está relacionado com a capacidade de repetir o máximo de potência após a realização de um exercício, o que é extremamente difícil devido, principalmente, a degradação do estoque de fosfocreatina (PCr) muscular, aumento da acidificação do meio intracelular e diminuição da coordenação neuromuscular (SILVA et al., 2011). Os resultados apresentados nos níveis elevados de Potência Máxima, Média e Mínima no Gênero Masculino (GM) em comparação ao Gênero Feminino (GF) em valores absolutos (Watts) e relativos (Watts/Kg) $(\mathrm{p}<0,05)$, podem ser explicados como os do estudo feito pelos autores Ikemoto et al. (2006), onde foi avaliada a Potência Muscular de Pico (Máxima) de 15 jovens do sexo masculino e 15 do sexo feminino através de preensão manual, e foi encontrada uma diferença entre os gêneros na Potência Máxima e as propriedades da curva de potência. A força muscular máxima apareceu em 30-50\% em homens, e em 20-40\% nas mulheres. Estas diferenças não são explicadas apenas pela influência da força, medidas antropométricas e diferenças neuromusculares, mas que outros fatores além da massa corporal magra, força nas pernas, e função neuromuscular podem estar operando no curto prazo, nas performances na Potência Máxima (MAYHEW \& SALM, 1990). Em um estudo mais recente de Perez-Gomez et al. (2008), onde determinaram as diferenças de gênero na corrida (sprints $30 \mathrm{e}$ $300 \mathrm{~m}$ ) e no ciclismo (Wingate test) em 123 homens e 32 mulheres. Os resultados apontaram que a Potência de Pico (Máxima) no teste de Wingate expressas por $\mathrm{kg}$ de Extremidades Inferiores de Massa Magra (EIMM) foi semelhante em homens e mulheres $(50,4 \pm 5,6$ e $50,5 \pm 6,2 \mathrm{Wkg}, \mathrm{p}=0,88)$. No entanto, quando a Potência Máxima foi expressa por $\mathrm{kg}$ de Peso Total, os homens atingiram um valor $\Delta 22 \%$ maior $(26,6 \pm 3,4 \mathrm{e}$ $21,9 \pm 3,2 \mathrm{Watts} / \mathrm{Kg}, \mathrm{p}=0,001)$ e no tempo de corrida menor em homens que em mulheres. Portanto, acreditase que o principal fator para as diferenças de gênero na Potência Máxima e Média é a massa muscular do peso corporal total.

Contudo, destaca-se que os valores encontrados das diferenças percentis absolutos $\Delta 78 \%$ (Watts) comparados aos valores relativos $\Delta 62 \%$ (Watts $/ \mathrm{Kg}$ ) na potência mínima entre os gêneros no presente estudo, conferiu-se aos atletas do Gênero Masculino (GM) nos primeiros sprints (potência máxima) do Runningbased Anaerobic Sprint Test (RAST), um aumento da compressão mecânica da vascularização do tecido ativo (KAGAYA \& HOMMA, 1997), resultando em níveis maiores de fatigabilidade dos atletas expressa pela diferença reduzida no valor percentil relativo (Watts/Kg) (HICKS; KENT-BRAUN \& DITOR, 2001).

Quanto as correlações mensuradas, a existente entre o VO2máx e a Potência Média apresentou valores mais altos $(\mathrm{r}=0.8227)$ do que a entre a potência máxima e o índice de fadiga $(\mathrm{r}=0.7326)$. Tomlin e Wenger (2001), em uma revisão acerca do assunto encontraram uma forte associação entre a aptidão aeróbia e a capacidade de sprints repetidos, corroborando os achados do presente estudo.

Forbes et al. (2009) explicam que, a ressíntese da Creatina Fosfato (PCr) é dividida em duas fases; fase inicial e a fase final. A fase inicial é contribuida pela produção glicolítica de ATPs e a fase final pela produção oxidativa de ATPs. Duteil et al. (2004), utilizando a quantificação da saturação da mioglobina, encontrou em atletas de resistência uma alta correlação $(r=0.75)$ entre a resaturação das moléculas de mioglobinas e a refosforilação da Creatina Fosfato (PCr), indicando uma maior capacidade oxidativa do que em atletas de sprints. Yoshida (2002) encontrou em (5) cinco corredores de longa distância uma diminuição significativa nas moléculas de Creatina Fosfato $(\mathrm{PCr})$ e menores níveis de acidificação em exercícios de flexão de joelho de alta intensidade em comparação com os (6) seis indivíduos sedentários.

Sabe-se que, a Creatina Kinase (CK) com a Creatina Fosfato (PCr) formam importante sistema metabólico de tamponamento em células com alterações na carga energética. Além da Creatina Kinase (CK) manter os níveis altos de ATPs durante a recuperação das contrações intensas, ela realiza o sequestro de $\mathrm{H}^{+}$ livres produzidos pela hidrólise de ATP diminuído a acidificação do meio intracelular e a diminuição das moléculas de Creatina Fosfato (PCr), mantendo desta forma um nível alto de Potência Média (ALLEN, LAMB \& WESTERBLAD, 2008).

Entretanto, há uma tendência de imprimir Potência Máxima solicitando uma maior necessidade de recrutamento das fibras tipo II, enquanto para maiores valores de VO2máx não existir esta obrigatoriedade, podemos inferir que o grupo estudado parece possuir características mais relacionadas a atividades aeróbicas. Em um outro estudo recente de Silva et al., (2011), envolvendo jogadores de futebol, não foi encontrada correlação entre o VO2máx e a Potência Máxima. Porém neste estudo os atletas tinham um VO2máx extremamente alto (média acima de $55 \mathrm{~mL} . \mathrm{kg}-1 . \mathrm{min}-1$ ), o que pode ter levado a esta baixa correlação. 


\section{CONCLUSÃO}

Os resultados encontrados no presente estudo nos permitem chegar a importantes conclusões, obviamente que respeitando as limitações inerentes a pesquisas desta natureza e as características específicas da amostra pesquisada.

As diferenças significativas encontradas nos valores de potências máxima, média e mínima, tanto em valores absolutos, quanto relativos na comparação entre os gêneros ratificam estudos anteriores relacionados ao mesmo tema, mesmo com populações diferentes das aqui mensuradas, assim como as também significantes diferenças quando analisado o VO2máx.

Chama a atenção e é importante enaltecer a alta correlação entre o VO2máx e a potência média, apontando para uma possível relação direta entre estes parâmetros, fato que, se confirmado, pode ajudar a entender resultados de atletas de vários níveis, além de servir como um importante parâmetro de auxílio para a prescrição de treinamento.

\section{REFERÊNCIAS}

AKALAN, C.; KRAVITZ, L.; ROBERGS, R.A. VO2max.: Essentials of the most widely used test in exercise physiology. Health \& Fitness Journal, vol. 08, n. 03, p. 5-9, 2004.

ALLEN, D.G.; LAMB, G.D.; WESTERBAD, H. Skeletal muscle fatigue: cellular mechanisms. Physiol Ver, vol. 88, n. 01, p. 287-332, 2008.

AZEVEDO, P.H.S.M.; OLIVEIRA, J.C.; SIMÕES, H.G.; BALDISSERA, V.; PEREZ, S.E.A. Cinética do consumo de oxigênio e tempo limite na vvo2máx: comparação entre homens e mulheres. Rev Bras Med Esporte, vol. 16, n. 04, p. 278-281, 2010.

CLARK, B.C.; COLLIER, S.R.; MANINI, T.M.; PLOUTZ-SNYDER, L.L. Sex differences in muscle fatigability and activation patterns of the human quadriceps femoris. Eur J Appl Physiol, vol. 94, n. 1-2, p. 196-206, 2005.

COOPER, K.N. The aerobics program for total well-being. Bantam Books: Toronto, New York, London , Sydney, Aucland,1982.

COOPER, K.N. Correlations between field and treadmill testing as a means for assessing maximal oxygen intake. JAMA 203:201, 1968.

DENADAI, B.S.; DENADAI, M.L.D.R.; GUGLIEMO, L.G.A. Taxa de remoção do lactato sanguíneo durante a recuperação passiva: efeitos do tipo de exercício e da capacidade aeróbia. Rev Paul de Educ Fís, vol. 10, n. 02, p. 113-121, 1996.

DUTEIL, S.; BOURRILHON, C.; RAYNAUD, J.S.; WARY, C.; RICHARDSON, R.S.; LERY-WILLIG, A.; JOUANIN, J.C.; GUEZENNEC, C.V.; CARLIER, P.G. Metabolic and vascular support for the role of myoglobin in humans: a multiparametric NMR study. Am J Physiol Regul Integr Comp Physiol, vol. 287, n. 06, p. 1441-1449, 2004. 
FORBES, S.C.; PAGANINI, A.T.; SLADE, J.M.; TOWSE, T.F.; MEYER, R.A. Phosphocreatine recovery kinetics following low- and high-intensity exercise in human triceps surae and rat posterior hindlimb muscles. Am J Physiol Regul Integr Comp Physiol, vol. 296, n. 01, p. 161-170, 2009.

GASTIN, P.B. Energy system interaction and relative contribution during maximal exercise. Sports Med, vol. 31, n. 10, p. 725-41, 2001.

GHANBARI-NIAKI, A.; KRAEMER, R.R.; SOLFANI, R. Plasma nesfatin-1 and glucoregulatory hormone responses to two different anaerobic exercise sessions. European Journal of Applied Physiology, vol. 110, $\mathrm{n}$. 04, p. 863-868, 2010.

HERDY, A.H.; UHLENDORF, D. Valores de referência para o teste cardiopulmonar para homens e mulheres sedentários e ativos. Arq Brás Cardiol, vol. 96, n. 01, p. 54-59, 2011.

HICKS, A.L.; KENT-BRAUN, J.; DITOR, D.S. Sex differences in human skeletal muscle fatigue. Exerc Sport Sci Rev, vol. 29, n. 03, p. 109-112, 2001.

HUNTER, S.K.; CRITCHLOW, A.; SHIN, I.S.; ENOKA, R.M. Men are more fatigable than strengthmatched women when performing intermittent submaximal contractions. J Appl Physiol, vol. 96, n. 21, p. 25-32, 2004.

IKEMOTO, Y.; DEMURA, S.; YAMAJI, S.; NAKADA, M.; KITABAYASHI, T.; NAGASAWA, Y. The characteristics of simple muscle power by gripping: gender differences and reliability of parameters using various loads. J Sports Med Phys Fitness. vol. 46, n. 01, p. 62-70, 2006.

JUNIOR, J.B.S.; CARVALHO, R.G.S.; FERREIRA, J.C.; SILVA, N.W.P.; SZMUCHROWSKI; L.A. Correlação entre os índices do teste de corrida com o teste de Wingate. Arquivos em movimento, vol. 4, n. 1, p. 12-22, 2008.

KAGAYA, A.; HOMMA, S. Brachial arterial blood flow during static handgrip exercise of short duration at varying intensities studied by a Doppler ultrasound method. Acta Physiol Scand, vol. 160, n. 03, p. 257-265, 1997.

LAMB, G.D.; RECUPERO, E.; STEPHENSON, D.G. Effect of myoplasmic pH on excitation-contraction coupling in skeletal muscle fibres of the toad. J Appl Physiol, vol. 448, p. 211-224, 1992.

MACENA, R.H.M. Contribuição da educação física na produção de conhecimento sobre a prática de atletismo na infância e na adolescência disponível em bases virtuais. Educação Física em Revista, vol. 5, n. 01, p. 01-20, 2011.

MAUGHAN, R.; HARMON, M.; LEIPER, J.; SALE, D.; DELMAN, A. Endurance capacity of untrained males and females in isometric and dynamic muscular contractions. Eur J Appl Physiol, vol. 55, n. 04, p. $395-400,1986$.

MAYHEW, J.L.; SALM, P.C. Gender differences in anaerobic power tests. Eur J Appl Physiol Occup Physiol, vol. 60, n. 02, p. 133-138, 1990. 
PEREZ-GOMEZ, J.; RODRIGUEZ, G.V.; ARA, I.; OLMEDILLAS, H.; CHAVERREN, J.; GONZÁLEZHENRIQUEZ, J.J.; DORADO, C.; CALBET, J.A. Role of muscle mass on sprint performance: gender differences? Eur J Appl Physiol, vol. 102, n. 06, p. 685-694, 2008.

SILVA, J.F.; GUGLIEMO, L.G.A.; DITTRICH, N.; FLORIANO, L.T.; ARINS, F.B. Relação entre aptidão aeróbia e capacidade de sprints repetidos no futebol: efeito do protocolo. Rev Bras Cienantropom Desempenho Hum, vol. 13, n. 02, p. 111-116, 2011.

TOMLIN, D.L.; WENGER, H.A. The relationship between aerobic fitness and recovery from high intensity intermittent exercise. Sports Med, vol. 31, n. 01, p. 01-11, 2001.

YOSHIDA, T. The rate of phosphocreatine hydrolysis and resynthesis in exercising muscle in humans using ${ }^{31}$ P-MRS. J Physiol Anthrolpol Appl Human Sci, vol. 21, n. 05, p. 247-255, 2002.

ZAGATTO, A.M.; BECK, W.R.; GOBATTO, C.A. Validity of the running anaerobic sprint test for assessing anaerobic power and predicting short-distance performances. Journal of Strength \& Conditioning Research, vol. 23, n. 06, p. 1820-1827, 2009. 